\title{
BARAÚNA: DIÁLOGO ENTRE NATUREZA E SOCIEDADE
}

\author{
Raí Vinícius Santos ${ }^{1}$
}

\section{Maria Betânia Moreira Amador²}

RESUMO: O trabalho trata da questão do verde na paisagem do Semiárido nordestino voltando-se para a Caatinga no intuito de subsidiar novas discussões e atentar para uma realidade eminente de extinção da Baraúna (Schinopesis brasiliensis) nessa região. O enfoque dado ao estudo dessa árvore no contexto da paisagem, caracteriza-se pela análise do meio ambiente com base no sistemismo e na complexidade. Salienta-se que este artigo resulta da pesquisa iniciada em agosto de 2012 e finalizada em agosto de 2013, cujo titulo "A Relação Natural e Social da Schinopesis brasiliensis (Braúna) com o meio Rural e Urbano numa Perspectiva de Paisagem Verde no Município de Calçado-PE" expressa preocupação com o processo de extinção da Baraúna no agreste de Pernambuco, especificamente no município de Calcado. Essa abordagem envolve, entre outros aspectos, as relações de diálogo do natural com o social trazendo-se uma reflexão sobre a importância desta árvore tanto na dinâmica natural, quanto nas relações de apego e pertencimento que o homem estabelece com elas. Nada nesta abordagem assume uma postura estática. O que move as compreensões ambientais é o dinamismo encontrado nas relações que se estabelecem. Neste sentido, toda a dimensão de afeto e histórias que se apresentam nessa contextualização é um convite ao universo cativante de relações quotidianas, do diálogo que existe entre o meio ambiente e o homem. A Baraúna, nesse contexto, pede que acordemos para pensar nela e nas demais árvores do semiárido.

Palavras chave: Baraúna. Sistemismo. Complexidade. Calçado-PE.

\footnotetext{
${ }^{1}$ Graduando em Geografia. UPE/ Campus Garanhuns. Email:rai.2vinicius@hotmail.com

${ }^{2}$ Prof $^{-}$Dr $^{\text {a }}$ em Geografia. UPE/ Campus Garanhuns. Email: betaniaamador@yahoo.com.br
} 


\section{INTRODUÇÃO}

O artigo é resultado do trabalho que se iniciou no âmbito do PFA/PIBIC/CNPq e apresenta os resultados que integraram e fomentaram a discussão sobre a Baraúna, (Schinopsis brasiliensis), num contexto sistêmico agregado às questões ambientais na relação do homem com a natureza. Para isso, fez-se necessário a interdisciplinaridade no que se refere à análise social e natural que, mediante essa interação, permitiu trazer o pensamento complexo proposto por Edgar Morin, o qual defende um diferente olhar paradigmático, não necessariamente novo, mas suficientemente transformador na abordagem da temática ambiental.

A existência da Baraúna no município de Calçado- PE levou à busca de argumentos que subsidiassem uma discussão sob o viés sistêmico voltado a paisagem verde e, no caso específico, a pesquisa centrou-se nas árvores do semiárido nordestino, e para ser mais preciso, da Caatinga, bioma único no mundo tendo-se como foco a espécie baraúna por ter existido em abundancia no passado e, atualmente, estar em processo de extinção no referido município.

Os elementos propostos nesta análise, afirmam estabelecer novas concepções àquelas que segregam as relações de diálogo entre o homem e o meio que, do ponto de vista geográfico, vai se reportar, não apenas a meras descrições, mas acima de tudo a buscar os fluxos concretos de interação do natural com o social. Assim, não foi observada qualquer paisagem como algo estático, mas sempre observada como algo dinâmico, que se abre e permite desvendar novas formas de vê-las tanto ligadas à sensibilidade e imaginação das pessoas, quanto a própria capacidade de transformação natural do meio.

Como já citado, esta análise se reporta a pesquisa que trouxe como tema "A Relação Natural e Social da Schinopsis brasiliensis (Braúna) com o Meio Rural e Urbano numa Perspectiva de Paisagem Verde no Município de Calçado-PE", a qual faz parte de um trabalho de maior porte sobre o verde do agreste tanto rural quanto urbano. Nesse contexto, reconhecer a Braúna ou Baraúna do sertão/agreste, como também é 
denominado, foi papel fundamental no caminhar desta pesquisa, podendo-se perceber o quanto a mesma é notável, sua importância para cada lugar no sentido de troca de benefícios com outras espécies e, também, da própria identidade de moradores e seu apego com elas.

A Braúna do Sertão, considerada árvore nobre é nativa dessa região. No bioma Caatinga, e, no estado de Pernambuco admite-se que há ocorrência de até dez indivíduos por hectare. As Schinopsis brasiliensis (Braúnas), de ordem sapendales da família anacordiaceas e gênero schinapes, são árvores espinhentas e de comportamento decíduo. As maiores árvores atingem dimensões próximas a $15 \mathrm{~m}$ de altura na idade adulta, sendo uma das maiores árvores da caatinga. As flores são pequenas, medindo de $3 \mathrm{~mm}$ a $4 \mathrm{~mm}$ de diâmetro, brancas, glabras e suavemente perfumadas. O fruto é uma drupa alada, medindo de $3 \mathrm{~cm}$ a $3,5 \mathrm{~cm}$ de comprimento, de coloração castanho-clara e cheia de massa esponjosa. A braúna apresenta crescimento lento, a idade de corte dá-se geralmente entre 20 a 30 anos. É uma espécie nobre da caatinga, como já descrito, e devido a grande variedade na sua utilização levou a uma exploração excessiva e sem reposição. Isso se seguiu ao quase esgotamento das reservas dessa espécie, sendo hoje considerada em perigo imediato de extinção, principalmente no nordeste do Brasil. Esse é o principal fator de seu corte ser proibido (EMBRAPA, 2009), e aqui fica a preocupação: quem fiscaliza essa proibição? Em termos de comercialização formal ate se admite haver fiscalização, mas no dia a dia do campo frente a necessidade de espaço para outras culturas e, principalmente pastos acredita-se que quem sabe ignora e quem nao sabe considera sua derrubada um ato natural e sem nenhuma consequência seja para o ambiente, seja para eles mesmos.

Objetivou-se analisar a Baraúna em sua funcionalidade, tanto natural, quanto social, inserida na área rural e urbana do município de Calçado-PE, num contexto sistêmico, atrelado a questões que envolvem o verde da paisagem, principalmente rural. Essa questão ligada ao verde abre um amplo debate em vários segmentos do contexto ambiental e propõe uma série de interconexões com várias áreas afins, mas na pesquisa em questão deu-se ênfase ao verde associado a uma função social e natural. Justifica-se pela necessidade do município conhecer e reconhecer a Baraúna como árvore de importância impar para a sociedade e para o meio natural, também pela relevância de se 
refletir e socializar a compreensão do objeto de estudo para evidenciar e discutir a questão da preservação e da sua função para a paisagem como parte de um sistema, bem como numa oportunidade posterior servir de subsídio para uma ação de extensão.

O estudo foi realizado no município de Calçado-PE, o qual está localizado na Mesorregião Agreste e na Microrregião Garanhuns do Estado de Pernambuco (Figura 1) fazendo parte do semiárido, distante $200,1 \mathrm{Km}^{2}$ do Recife e destaca-se pela produção agrícola de feijão. A temperatura média anual é de $22,1 \stackrel{\circ}{ } \mathrm{C}$.

Mapa de Localização do Município de

Calçado - Pernambuco

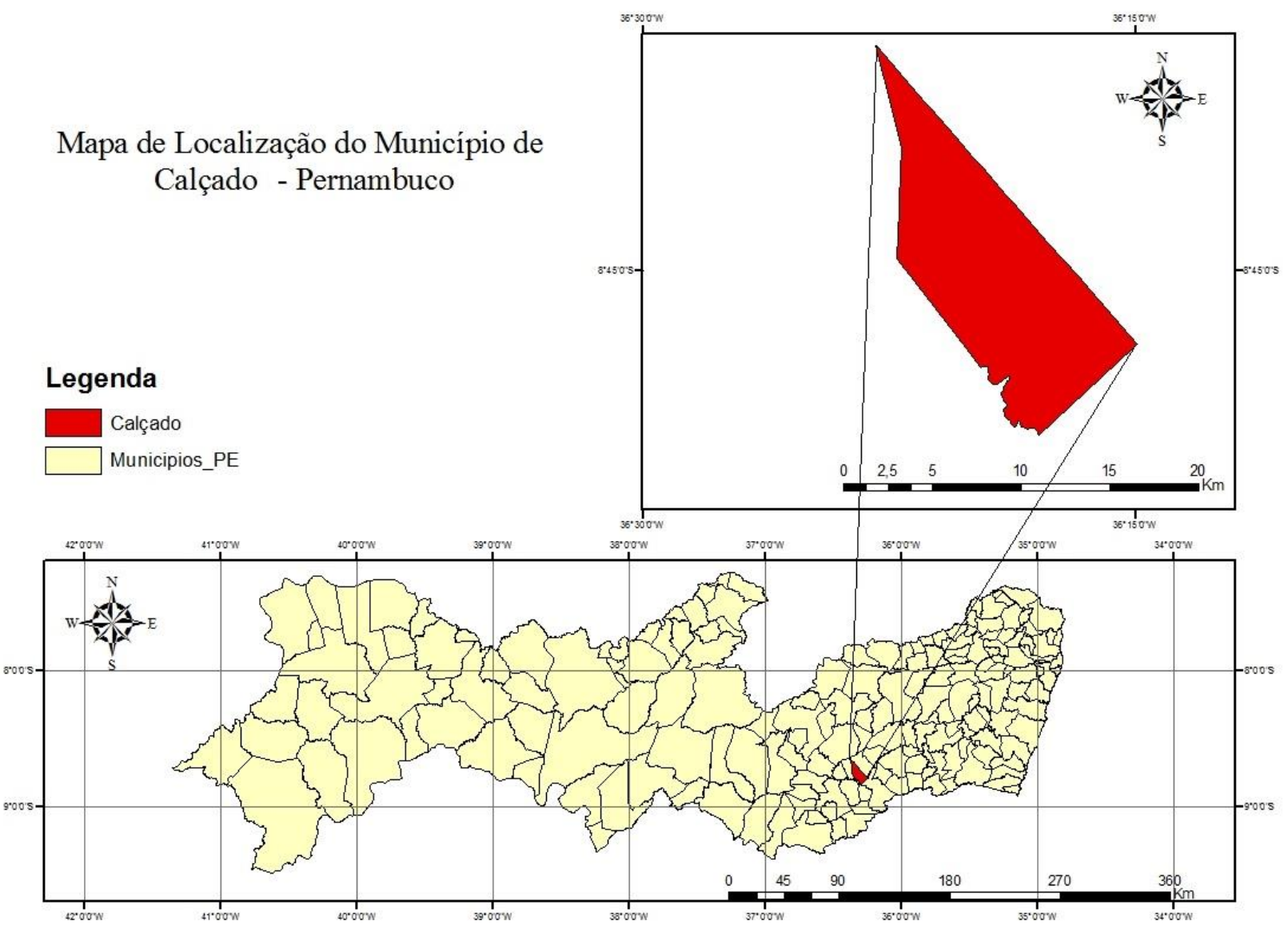

Figura 1: Localização do município de Calcado - PE. Adaptado por Raí Vinicius, 2013.

A metodologia adotada na pesquisa materializou-se pelo levantamento bibliográfico, bem como a ida ao campo para observações e entrevistas, algumas tendo como objetivo o resgate de história oral que expressassem essa conotação de diálogo entre o objeto de estudo e o cotidiano das pessoas. Em termos de procedimento, mostrou-se, também, necessário a interdisciplinaridade no trato de questões expostas no projeto, bem como o uso da percepção como ferramenta de analise da paisagem, a qual é peça fundamental 
numa pesquisa voltada a temática sobre meio ambiente. Houve também aplicação de questionários associados à entrevistas aos moradores próximos do objeto de estudo e, sempre que possível utilizou-se a máquina fotográfica para tomada de algumas fotos importantes na documentação do trabalho de campo.

$\mathrm{Na}$ identificação da Baraúna, no município de Calçado, inicialmente realizou-se uma busca aos sítios que estão inseridos na área de estudo. Procurou-se, também, o conhecimento, mesmo que preliminar, dessa árvore na dinâmica de cada localidade. Cabe salientar, ainda, que esta pesquisa integra trabalhos no Grupo de Estudos Sistêmicos do SemiÁrido do Nordeste - GESSANE compondo o projeto denominado "O verde na paisagem agreste de Pernambuco: urbano e rural" que visa obter um quadro da situação do verde urbano e rural de municípios na área de abrangência de Garanhuns, considerado polo educacional, turístico e comercial na microrregião considerada.

\section{DESENVOLVIMENTO}

Na pesquisa desenvolvida houve a percepção da importância da Baraúna tanto para sociedade quanto para a própria dinâmica natural. No município de Calçado, foi encontrada a árvore em alguns dos sítios, quais sejam: o Sítio Pitombeira, Boa Vista, Mocós, Riacho Dantas, Olho d’agua Velho e Várzea do Gado. Cabe salientar que destes citados, o Sítio Pitombeira se sobressai por uma quantidade maior de árvores dessa espécie. As fotos mostradas abaixo são de baraúnas no Sítio Pitombeira (Figura 2). 


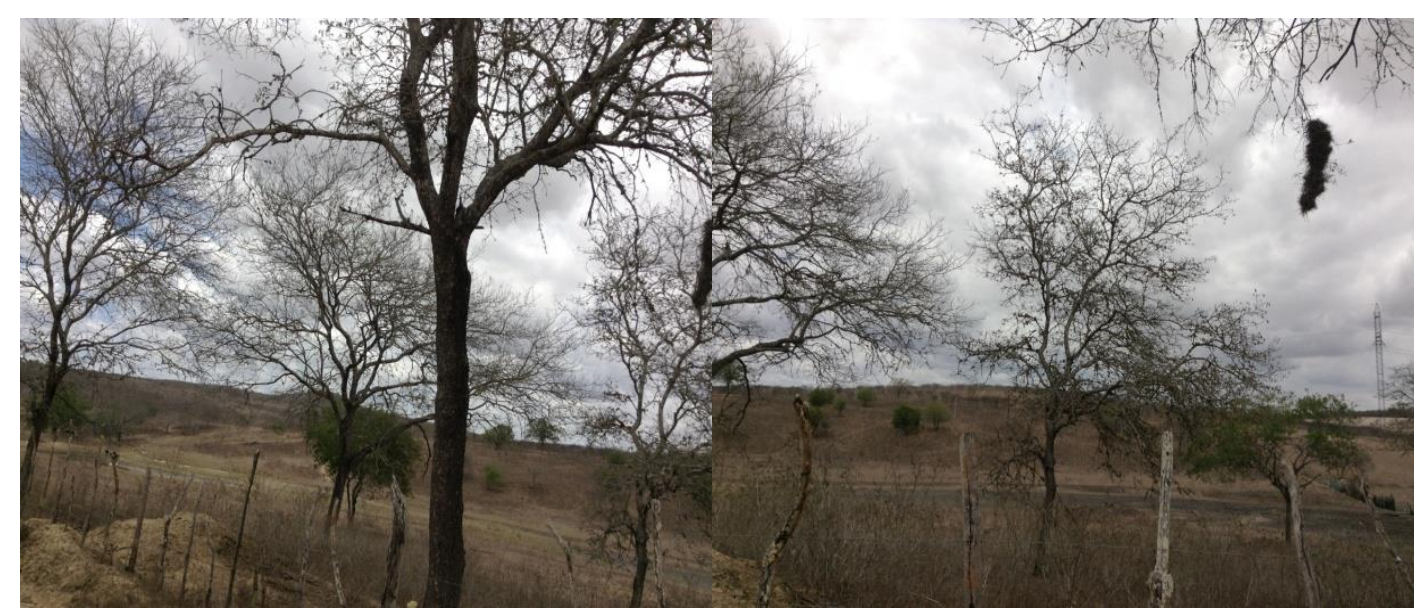

Figura 2: Baraúnas no Sitio Pitombeiras em Calcado - PE, 2013. Foto: Rai Vinícius, 2013.

O relacionamento dessa árvore com o ser humano remete a uma sensação de lembranças que, por muitas vezes gera apego, pois se apresentam como objeto causador dessas lembranças. Caracterizando-se essa visão de apego, cabe abordar, de forma sucinta, algumas características que em uma conversa com uma moradora em um dos sítios visitados e com quantidade significativa de baraúnas no entorno de sua casa e de suas terras. A mesma fala justamente da relação que têm com essas árvores e dos sentimentos que the são causados, os quais remetem à lembranças dos "bons tempos", conforme suas palavras, pois seu falecido marido tinha um forte apego a essas árvores, e, portanto, ela absorveu dele esse sentimento de apego e tornou-se uma defensora tenaz das baraúnas e de todas as árvores de grande porte do semiárido e, finalizando esse contexto, esta senhora não deixa de modo algum o corte de grandes árvores em suas terras. Espera-se, no entanto, que seus descendentes tenham absorvido esses valores e consigam projeta-los para outras gerações de herdeiros coadunando-se, assim, com uma das mais importantes premissas da sustentabilidade ambiental, a qual pode ser entendida como um princípio.

O principio da sustentabilidade coloca a preservação e a conservação dos recursos naturais como condição essencial para a reprodução socioeconómica da sociedade seja ela urbana ou rural (MARTINS; SOARES, 2010, p. 149 apud AMADOR, 2011, p.52). 
A Baraúna é uma espécie da Caatinga e, devido a grande variedade de sua utilização devido ser madeira considerada "nobre", levou a uma exploração excessiva e sem reposição. Consequentemente, isso levou ao quase esgotamento das reservas dessa espécie, sendo hoje considerada em perigo imediato de extinção principalmente no nordeste do Brasil. Esse é o principal fator de seu corte ser proibido, e a pesquisa vêm reafirmar veementemente esse fato.

Ressalta-se nesse ponto que de acordo com Tarsa (2008, p. 33 - 34 apud ARRUDA, 2013, p. 97), "A Caatinga é, hoje, uma das regiões do planeta mais ameaçadas pela exploração humana predatória e é uma das menos protegidas" além de ser comprovadamente um dos ecossistemas de ecologia frágil e pouco conhecido, além de sujeito ao processo de desertificação como ja preconizado décadas atrás pelo ecólogo Vasconcelos Sobrinho.

As discussões que envolvem as questões ambientais demandam atenções no meio acadêmico favorecendo, assim, o surgimento de pesquisas nas quais a complexidade presente nesse tema contribua para refletir a necessidade da importância colaborativa tanto entre os professores das diversas áreas do conhecimento, quanto para a população em geral, pois se acredita que o trabalho sistêmico e interdisciplinar que também é complexo contribui na relação intrínseca que existe entre o homem e o meio. Então, a discussão sobre a temática ambiental que se estendeu desde o naturalismo passando por varias vertentes do pensamento moderno e pós-moderno, não conseguiu tratar adequadamente desses dois segmentos da ciência humana e natural, de forma integrada mas que, conforme o tempo passa, cada vez mais se vai estreitando e ficando quase que impossível serem trabalhadas de forma segregada. Assim, ao se descobrir que o meio ambiente afirma as complexas interrelações entre o social e o natural, ambos em constante transformação, começam a surgir várias discussões no meio acadêmico e o aparecimento de muitos trabalhos que evidenciam a problemática nesse contexto. Tornase relevante, em consequência, uma ampla discussão que se integre em diversas áreas do saber, onde o pensamento complexo possa tomar para si o tema e o abordar sob a ótica fundamental das relações que se estabelecem na discussão de ambos os contextos, perfazendo um caminho de diálogo entre eles. 
O dialogo nesse contexto, por sua vez, exige o imaginário presente na sociedade e a humildade do pensar científico. Mas, mesmo assim, ainda considera-se insuficiente frente a falta de sensibilidade para questões dessa natureza vindas, principalmente, do sector administrativo em todas as esferas hierárquicas, o qual vive e segue o sistema económico reinante em sua plenitude. Constata-se que a realidade e ecossistemica e, portanto dinâmica, ao mesmo tempo humana e subjetiva, artificial e objetiva.

\section{CONCLUSÃO}

O pensamento complexo na questão ambiental, trazida por Edgar Morin, vem ao encontro de uma nova reflexão sobre a questão em pauta, deixando de ser apenas natural e passando a se relacionar à social, proporcionando novas discussões e o surgimento de novos paradigmas em várias áreas do conhecimento, além do conceito de uma organização sistêmica quebrando, assim, preconceitos e tabus que pudessem existir sobre o meio ambiente e o uso dessa expressão. Essa questão abriu as portas ao despertar ecológico tratado por Alfredo Pena-Vega que, calcado nas concepções complexas do próprio Edgar Morin, escreveu sobre as intrínsecas relações de dependências e independências do homem e do meio como integrante de um sistema, e, sem esquecer, contudo, da questão da preservação do meio ambiente que se tornou de relevante importância devido aos muitos desequilíbrios ecológicos, respaldado também numa reorganização epistemológica colocada pelo Michel Foucault (1966), como salientado por Pena-Vega em sua obra "O Despertar Ecológico" (2003), o que possibilitou novas visões sobre ecologia.

Essa visão de sistemas, colocada para tornar o meio ambiente parte dinâmica relacionada à ação humana, foi tido como principal método de abordagem que evidenciasse, justamente essa relação existente entre o natural e o social, pois na evolução do pensamento geográfico, desde sua sistematização, com Humboldt que era naturalista e Ritter que descrevia as organizações espaciais dos homens sobre os diferentes lugares, atrelaram-se a essas vertentes, porém com dissociações que ao mesmo tempo as separavam. Mais tarde, Ratzel propôs uma visão do determinismo dos 
lugares sobre o homem, contrapondo a isso, La Blache concebia as possibilidades que o homem poderia ter sobre o meio, e a separação entre elementos físico-naturais e elementos humano-sociais. No entanto, nenhuma dessas concepções conseguiu interrelacionar sistemicamente o homem com o meio natural.

Seguindo-se a discussão do pensamento complexo e a ideia de sistemas, é notável que nem o método positivista, que não conseguia associar a questão física à humana, nem o marxismo, que partia da crítica do homem e sua sociedade, foram capazes de conceber em seus estudos as relações complexas do meio ambiente, sendo a teoria de sistemas o principal método encarregado do estudo dessa área. Por volta dos anos 1930, surge a abordagem sistêmica defendida e divulgada por Ludwig von Bertalanffy, biólogo alemão e que, só décadas depois teve a obra Teoria dos Sistemas difundida em praticamente todas as áreas da ciência.

\footnotetext{
Chegamos então a uma concepção que, por oposição ao reducionismo, podemos denominar perspectivismo. Não podemos reduzir os níveis biológico, social e do comportamento ao nível mais baixo, o das construções e leis da física. Podemos contudo encontrar construções e possivelmente leis nos níveis individuais [...]. O principio unificador e que encontramos organização em todos os níveis (BERTALANFFY, 2009, p. 76).
}

Assim a baraúna, árvore tão importante na dinâmica natural do semiárido, é um grandioso e ao mesmo tempo pequeno elemento de uma discussão que abrange diversas concepções e que busca essa imersão harmoniosa na relação do homem com seu meio. A pesquisa, sem dúvida alcançou suas expectativas, pois a cada passo dado pode-se desvendar essa fascinante dimensão do envolvimento cotidiano e histórico da vida do ser humano totalmente ligado a vida natural e, nesse caso especifico, ao elemento Baraúna.

\section{REFERÊNCIAS}

ALBUQUERQUE, U. P. de; ANDRADE, L. de H. C. Conhecimento botânico tradicional e conservação em uma área de Caatinga no Estado de Pernambuco, Nordeste do Brasil. Acta BotanicaBrasilica, São Paulo, v. 16, n. 3, p. 273-285, 2002. 
ALBUQUERQUE, U. P. de; ANDRADE, L. de H. C.; SILVA, A. C. O. de. Use of plant resources in a seasonal dry forest (Northeastern Brazil). Acta BotanicaBrasilica, São Paulo, v. 19, n. 1, p. 27-38, 2005. ALCOFORADO FILHO, F. G. .

AMADOR, Maria Betânia Moreira. Sistemismo e sustentabilidade: questão interdisciplinar. São Paulo: Scortecci, 2011.

ARRUDA, Lucielma Bernardino Coelho de. Alfabetizacao ecológica: a caatinga como ponto de partida. In: SOUZA, Debora Quetti Marques de (Org.). Educação em debate: tópicos atuais. Recife: Editora Universitaria da UFPE, 2013.

BERTALANFFY, Ludwig von. Teoria geral dos sistemas: fundamentos, desenvolvimento e aplicações. 4 ed. Tradução de Francisco M. Guimaraes. Petropolis, Rio de Janeiro: Vozes, 2009.

GUIMARÃES, Solange T. de Lima: Percepção Ambiental: Paisagem e Valores. OLAMCiência e Tecnologia. № 2 / 2009 <Disponível em: HTTP// www. cecemca.rc.unesp.br/ojs/índex-php/olam/índex>. Acesso em 03/06/2013.

MIRANDA, Ana Maria: Percepção Ambiental: o despertar para o conhecimento científico através de uma horta. 2008 <Disponível em HTTP//www.gd.g12.br/eegd>. Acesso em 18/03/2012.

PENA-VEGA, Alfredo; O Despertar Ecológico: Edgar Morin e a ecologia complexa. Tradução: Renato Cavalheira e Elimar Pinheiro do Nascimento. Rio de Janeiro: Garamond, 2003.

TUAN, Yu Fu: Topofilia: um estudo da percepção, atitudes e valores do meio ambiente. São Paulo: Ed. Difel, 1980.

VASCONCELOS SOBRINHO, J. As regiões naturais do nordeste, o meio e a civilização. Recife: CONDEPE, 1970: Companhia Editora de Pernambuco, 2005 (reimpressão). 